\title{
UTILIZAÇÃO DE MODELOS PARA CORRELACIONAR DADOS EXPERIMENTAIS DE SOLUBILIDADE DO FERTILIZANTE NITROGENADO UREIA EM MISTURAS HIDRO-ALCOÓLICAS
}

\author{
M.C. OLIVEIRA ${ }^{1}$, A.P. SILVA ${ }^{1}$, R.A. MALAGONI ${ }^{1}$ \\ ${ }^{1}$ Universidade Federal de Uberlândia / Faculdade de Engenharia Química \\ E-mail para contato: malagoni@feq.ufu.br
}

\begin{abstract}
RESUMO - Dados de solubilidade de compostos químicos em água são fundamentais no projeto de colunas de separação de poluentes orgânicos, extratores, evaporadores e unidades de absorção. A falta de dados experimentais de solubilidade de solutos em solventes limita estudos de desenvolvimento de modelos preditivos. A ureia é o fertilizante nitrogenado mais utilizado no mundo, sendo aplicada via solo, no plantio ou em cobertura. Dados de solubilidade de ureia em água são importantes para uma adequada aplicação deste fertilizante na lavoura. O objetivo deste trabalho foi correlacionar dados experimentais de solubilidade da ureia em misturas hidroalcoólicas utilizando e modificando modelos encontrados na literatura. Os valores de solubilidade foram ajustados em função da temperatura de equilíbrio e da fração de álcool (etanol e isopropanol) presente na mistura álcool + água. Os desvios relativos foram determinados comparando-se os valores preditos pelos modelos com os dados experimentais.
\end{abstract}

\section{INTRODUÇÃO}

De acordo com Andrade et al. (2004), solubilidade, por definição, é a concentração de soluto dissolvido em um solvente em equilíbrio com o soluto não dissolvido à temperatura e pressão especificadas, ou seja, é a medida da quantidade máxima de soluto que pode ser dissolvida em um determinado solvente.

Lee e Lahti (1972) estudaram a solubilidade da ureia em água, metanol, etanol e isopropanol e em misturas. Para a mistura de isopropanol+água, foram estudadas as composições de 33,3\% e $66,7 \%$ (em volume) de isopropanol.

O objetivo deste trabalho foi correlacionar dados experimentais de solubilidade da ureia em misturas hidro-alcoólicas utilizando e modificando modelos encontrados na literatura.

\section{MATERIAIS E MÉTODOS}

O ajuste dos dados encontrados foi feito a partir do uso de diferentes modelos empíricos e, também, utilizando polinômios de primeiro e terceiro grau. Os valores de solubilidade em função da temperatura foram inseridos no software utilizado e foi feito o ajuste não linear dos dados apresentados, inserindo os modelos e obtendo separadamente todos os parâmetros, gráficos, 
desvio e resíduos. A Equação 1 apresenta o modelo proposto por Lee e Lahti (1972), no estudo da solubilidade da ureia em misturas de solventes.

$$
\ln S=A+B T
$$

Além do modelo empírico, os dados foram ajustados a um modelo linear, segundo a Equação 2.

$$
S=A T+B
$$

\section{RESULTADOS E DISCUSSÃO}

\subsection{Ajuste de dados}

Os dados de solubilidade da ureia em isopropanol + água de Castro et al. (2012) foram ajustados a partir da equação de Lee e Lahti (1972) e do modelo linear e o ajuste está repostado na Figura 1. O ajuste dos dados de solubilidade da ureia em etanol + água de Carvalho et al. (2012) também foi obtido através da equação de Lee e Lahti (1972) e modelo linear e está demonstrado na Figura 2.

Todas as equações utilizadas representaram bons ajustes para os dados da literatura e também foram avaliados outros aspectos para escolha da melhor equação de ajuste.

Observando os gráficos e as tabelas e ainda considerando um nível de significância de 5\%, todos os parâmetros das equações foram significativos para as duas misturas de solvente. Para escolher o modelo que melhor representou os dados experimentais analisou-se o R2, valor do parâmetro, erro padrão do parâmetro e nível de significância, conclui-se que o modelo proposto por Lee e Lahti (1972) foi o que melhor representou os dados experimentais para as duas misturas de solvente.

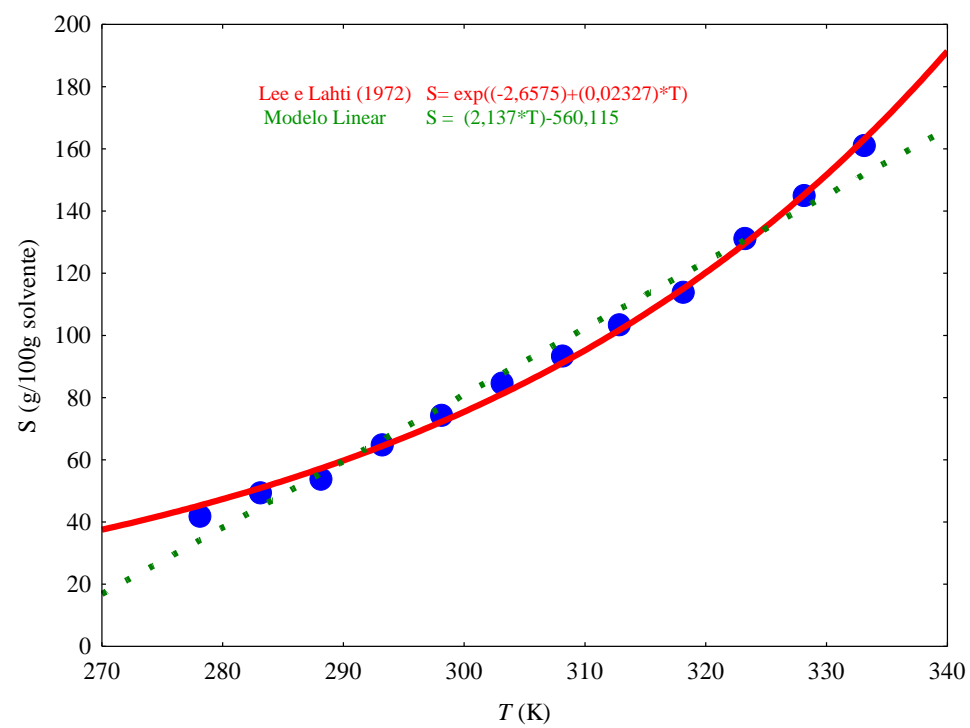

Figura 1 - Ajuste dos dados de solubilidade da ureia em isopropanol + água de Castro et al. (2012) 


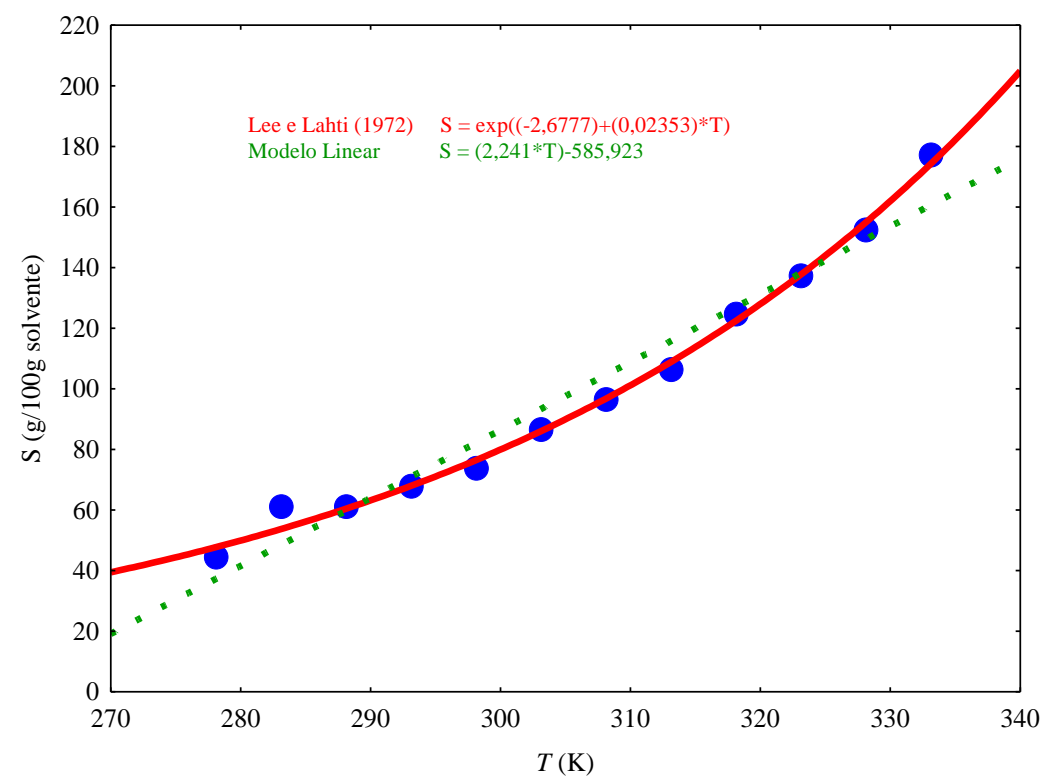

Figura 2 - Ajuste de dados de solubilidade da ureia em etanol + água de Carvalho et al. (2012)

As Tabelas 1 e 2 apresentam os valores dos parâmetros e dos desvios para as equações utilizadas neste trabalho (Equações 1 e 2) usadas para o ajuste dos dados de solubilidade da ureia em ambas misturas de solventes.

Tabela 1 - Parâmetros dos ajustes de solubilidade da ureia em isopropanol + água de Castro et al. (2012)

\begin{tabular}{cccc}
\hline \multicolumn{2}{c}{ Lee e Lahti (1972) } & \multicolumn{2}{c}{ Modelo Linar } \\
\hline Parâmetro & Erro Padrão & Parâmetro & Erro Padrão \\
$A=-2,6575$ & 0,1545 & $A=2,137$ & 0,089 \\
$B=0,02327$ & 0,00049 & $B=-560,115$ & 27,294 \\
\hline \multicolumn{2}{c}{$\mathrm{R}^{2}=0,9982$} & \multicolumn{2}{c}{$\mathrm{R}^{2}=0,9914$} \\
\hline
\end{tabular}

Tabela 2 - Parâmetros dos ajustes de solubilidade da ureia em isopropanol + água de Carvalho et al. (2012)

\begin{tabular}{cccc}
\hline \multicolumn{2}{c}{ Lee e Lahti (1972) } & \multicolumn{2}{c}{ Modelo Linar } \\
\hline Parâmetro & Erro Padrão & Parâmetro & Erro Padrão \\
$A=-2,6777$ & 0,1880 & $A=2,241$ & 0,1478 \\
$B=0,02353$ & 0,00059 & $B=-585,923$ & 45,2509 \\
\hline \multicolumn{2}{c}{$\mathrm{R}^{2}=0,9982$} & \multicolumn{2}{c}{$\mathrm{R}^{2}=0,9914$} \\
\hline
\end{tabular}

\subsection{Cálculos dos desvios relativos}

Para assegurar a escolha do melhor modelo para ajuste dos dados, foi analisado o resíduo obtido utilizando o modelo de Lee e Lahti, já que ele foi o que apresentou o menor desvio e todos os parâmetros significativos. As Tabelas 3 e 4 reportam os valores observados, preditos e os 
resíduos obtidos no ajuste utilizando o modelo de Lee e Lahti para os dados de Castro et al. (2012) para a mistura de isopropanol + água e Carvalho et al. (2012) para a mistura etanol + água, respectivamente.

De acordo com os dados reportados nas Tabelas 3 e 4, o modelo de Lee e Lahti ajusta-se de maneira satisfatória aos dados da curva de solubilidade da ureia em mistura isopropanol + água e etanol + água por apresentar valores residuais baixos. Ele também apresentou todos os parâmetros significativos considerando um nível de significância de $5 \%$.

Tabela 3- Resíduos obtidos no estudo da solubilidade da ureia em isopropanol +água usando o modelo de Lee e Lahti (1972)

\begin{tabular}{cccc}
\hline $\boldsymbol{T}(\mathbf{K})$ & Valor Observado & Valor Previsto & Resíduo \\
\hline 278,15 & 41,8480 & 45,3836 & $-3,53563$ \\
283,15 & 49,3160 & 50,9836 & $-1,66759$ \\
288,15 & 53,7930 & 57,2746 & $-3,48155$ \\
293,25 & 64,7980 & 64,4917 & 0,30634 \\
298,15 & 74,3160 & 72,2810 & 2,03500 \\
303,15 & 84,6170 & 81,1999 & 3,41712 \\
308,15 & 93,3670 & 91,2193 & 2,14772 \\
312,85 & 103,4140 & 101,7621 & 1,65192 \\
318,15 & 113,8540 & 115,1196 & $-1,26556$ \\
323,25 & 131,1290 & 129,6257 & 1,50334 \\
328,15 & 144,9160 & 145,2819 & $-0,36592$ \\
333,15 & 161,0060 & 163,2085 & $-2,20252$ \\
\hline
\end{tabular}

Tabela 4 - Resíduos obtidos usando o modelo de Lee e Lahti (1972) para solubilidade da ureia em etanol + água

\begin{tabular}{cccc}
\hline $\boldsymbol{T}(\mathbf{K})$ & Valor Observado & Valor Previsto & Resíduo \\
\hline 278,15 & 44,4400 & 47,7985 & $-3,35846$ \\
283,15 & 61,1100 & 53,7660 & 7,34402 \\
288,15 & 61,1100 & 60,4785 & 0,63146 \\
293,15 & 67,8800 & 68,0291 & $-0,14915$ \\
298,15 & 73,6600 & 76,5224 & $-2,86243$ \\
303,15 & 86,5400 & 86,0761 & 0,46393 \\
308,15 & 96,3200 & 96,8225 & $-0,50247$ \\
313,15 & 106,3900 & 108,9105 & $-2,52053$ \\
318,15 & 124,5100 & 122,5078 & 2,00224 \\
323,15 & 137,2700 & 137,8026 & $-0,53256$ \\
328,15 & 152,4300 & 155,0069 & $-2,57689$ \\
333,15 & 177,0400 & 174,3591 & 2,68086 \\
\hline
\end{tabular}




\section{CONCLUSÃO}

De acordo com os dados obtidos na literatura foi possível observar que a solubilidade da ureia aumentou com o aumento da temperatura. Também, o aumento da concentração de álcool na mistura ocasionou o decréscimo na solubilidade.

Todos os modelos utilizados para ajuste dos dados de solubilidade apresentaram coeficiente de determinação próximo a 1 . Isso mostrou que é necessário avaliar vários aspectos antes de escolher a equação que melhor se ajustou aos dados. Para uma avaliação precisa também foi levado em conta o desvio e o resíduo obtido para os diferentes modelos.

A partir de todas as avaliações foi possível observar que o modelo de Lee e Lahti (1972) foi o que forneceu melhor ajuste dos dados, uma vez que foi o modelo que apresentou todos os parâmetros significativos e baixos valores de desvio e resíduo, quando comparados os dados da literatura com os valores preditos pela equação.

\section{NOMENCLATURA}

$A$ - parâmetro da Equação de Lee e Lahti e modelo linear

$B$ - parâmetro da Equação de Lee e Lahti e modelo linear

$S$ - solubilidade (g/100g solvente)

$T-$ temperatura $(\mathrm{K})$

\section{AGRADECIMENTOS}

Agradecemos a Fundação de Amparo à Pesquisa do Estado de Minas Gerais (FAPEMIG) pelos recursos concedidos no Projeto de Participação Coletiva em Eventos Técnicos-Científicos (PCE-00082-14) e a Faculdade de Engenharia Química da Universidade Federal de Uberlândia pela estrutura física disponibilizada para a realização desta pesquisa.

\section{REFERÊNCIAS}

ANDRADE, J. B.; MARTINS, C. R.; SILVA, L. A. Porque todos os nitratos são solúveis? Quim. Nova; Vol. 27, No. 6, 1016-1020, 2004.

CASTRO, C. C.; CARVAlho, N. D.; LOBATO, F. S.; MALAGONI, R. A. Solubilidade da ureia em etanol+água. In: XIX COBEQ - Congresso Brasileiro de Engenharia Química, 2012, Búzios - RJ. Anais do XIX COBEQ, 2012. p. 5421-5430.

HEIDMAN, J. L.; TSONOPOULOS, C.; BRADY, C. J.; WILSON, G. M. high temperature mutual solubilities of hydrocarbons and water. Part II: ethylbenzene, ethylcyclohexane and n-octane. AICHE J., 31, 3, p. 373-384, 1985.

LEE, F-M.; LAHTI, L. E. Solubility of urea in water-alcohol mixtures. J. Chem. and Eng. Data, v. 17, n. 3, p. 304-306, 1972.

YAWS, C. L.; LIN, X.; BY, L. The water solubility of naphtenes. Chem. Eng., p. 122-123, 1993. 